\title{
Aprendizaje Complejo a través de las TIC en las Universidades Venezolanas
}

\section{Aprendizagem Complexa através das TIC nas Universidades Venezuelanas}

\author{
Complex Learning through ICT in Venezuelan Universities
}

\author{
Hebert Elías Lobo Sosa ${ }^{1}$ \\ Ana Carolina Pacheco Millan ${ }^{2}$ \\ Jesús Ramón Briceño Barrios ${ }^{3}$
}

\begin{abstract}
Resumen
El aprendizaje complejo constituye un constructo conceptual que busca vincular los procesos cognitivos, volitivos y afectivos, que forman parte del aprendizaje del ser humano, explicado por múltiples enfoques y teorías (Aprendizaje por interacción cultural, Aprendizaje cognitivista, Teoría de los campos conceptuales, Inteligencia emocional, Inteligencias múltiples, Aprendizaje significativo, Aprendizaje por descubrimiento), con la naturaleza compleja del universo, siguiendo la ruta del Pensamiento complejo de Morin, rompiendo con el esquema de fragmentación de las disciplinas científicas. Se plantea cómo favorecer este proceso a partir de las potencialidades que poseen las tecnologías de la información y la comunicación (TIC), superando las limitaciones de recursos institucionales y los dilemas planteados para docentes y estudiantes, en el contexto universitario venezolano, mediante una propuesta de un modelo de construcción, difusión e intercambio de conocimientos en redes complejas de aprendizaje, porque como queda demostrado, aunque es importante disponer de los recursos tecnológicos, para obtener resultados en la formación de profesionales universitarios con conocimientos amplios e integrales, no es suficiente, pues, dependiendo de la forma cómo se usen y administren tales recursos, la respuesta puede ser totalmente diferente, según se incorporen al conjunto de relaciones interpersonales de profesores y alumnos. Se plantea un modelo de integración de las TIC innovador basado en redes de aprendizaje complejas, que tienen como sustento las teorías siguientes: la Acción comunicativa (Habermas), General de sistemas (Bertalanffy), Pensamiento complejo (Morin) e Inteligencias múltiples (Gardner).
\end{abstract}

Palabras claves: Aprendizaje; Complejidad; TIC; Universidades venezolanas, Modelos de integración TIC.

\section{Resumo}

A aprendizagem complexa é um construto conceitual que busca articular processos cognitivos, volitivos e afetivos, que fazem parte da aprendizagem humana, explicados por múltiplas abordagens e teorias

\footnotetext{
${ }^{1}$ Doctor en Educación (ULA), Magister Arteum en Ciencias Aplicadas (Física), Especialista en Enseñanza de la Educación Superior, Ingeniero Civil. Profesor Titular (Jubilado) Universidad de Los Andes-NURR (1986-2018). Departamento de Física y Matemática. Área de Física. Trujillo-Venezuela. Profesor Visitante FURG (20182020), IE - Instituto de Educacão - Programa de Pós-Graduação de Educação em Ciências: Quimica da Vida e Saúde (PPGEC). RS-Brasil; helobos.brasil@gmail.com

${ }^{2}$ Licenciada en Educación, mención Lenguas Extranjeras, Maestrante del Programa de Maestría en Gerencia Educativa del CRIHES. ULA-NURR. Profesora Instructora de la Universidad de Los Andes (2017-2018). Departamento de Lenguas Modernas. Área de Francés; pachecomillananacarolina@gmail.com

${ }^{3}$ Doctor en Educación (UFT), Magister Scientarum en Sistemas de Control (ULA), Doctor en Física (UM). Profesor Titular (Jubilado) Universidad de Los Andes-NURR (1986-2018). Departamento de Física y Matemática. Área de Física. Trujillo-Venezuela. Profesor Visitante FURG (2018-2020), IMEF - Instituto de Matemática, Estatística e Física - Mestrado Profissional em Ensino de Física (MNPEF). RS-Brasil; jesusrbb@gmail.com
} 
(Aprendizagem cognitivista, Aprendizagem por interação cultural, Teoria dos campos conceituais, Inteligência emocional, Inteligências múltiplas, Aprendizagem significativa, Aprendizagem por descoberta) com a natureza complexa do universo, seguindo o caminho do Pensamento complexo de Morin, rompendo com o esquema de fragmentação das disciplinas científicas. Considera como favorecer este processo com base no potencial das tecnologias de informação e comunicação (TIC), superando as limitações de recursos institucionais e os dilemas levantados para professores e alunos, no contexto universitário venezuelano, através de uma proposta de modelo de construção, difusão e troca de conhecimento em redes complexas de aprendizagem, porque, como foi demonstrado, embora seja importante ter os recursos tecnológicos, para obter resultados na formação de profissionais universitários com conhecimento amplo e abrangente, não é suficiente, então, dependendo da maneira como esses recursos são usados e gerenciados, a resposta pode ser totalmente diferente, dependendo de como eles são incorporados ao conjunto de relações interpessoais de professores e alunos. Propõe-se um modelo inovador de integração de TIC baseado em redes complexas de aprendizagem, baseado nas seguintes teorias: Ação Comunicativa (Habermas), Sistemas Gerais (Bertalanffy), Pensamento Complexo (Morin) e Inteligências Múltiplas (Gardner)

Palavras-chave: Aprendizagem; Complexidade; TIC; Universidades venezuelanas; Modelos de integração de TIC

\begin{abstract}
Complex learning is a conceptual construct that seeks to link the cognitive, volitional and affective processes, which are part of the learning of the human being, explained by multiple approaches and theories (Learning by cultural interaction, Cognitive learning, Theory of conceptual fields, Emotional intelligence, Multiple intelligences, Meaningful learning, Learning by discovery), with the complex nature of the universe, following the path of the complex thought of Morin, breaking with the scheme of fragmentation of scientific disciplines. It is proposed how to favor this process based on the potential of information and communication technologies (ICTs), overcoming the limitations of institutional resources and the dilemmas proposed for teachers and students, in the Venezuelan university context, through a proposal of a model of construction, dissemination and exchange of knowledge in complex learning networks, because as it is demonstrated, although it is important to have the technological resources, to obtain results in the training of university professionals with broad and comprehensive knowledge, it is not enough, , depending on the way these resources are used and managed, the answer may be totally different, depending on how they are incorporated into the set of interpersonal relationships of teachers and students. An innovative ICT integration model based on complex learning networks is proposed, based on the following theories: Communicative Action (Habermas), General Systems (Bertalanffy), Complex Thinking (Morin) and Multiple Intelligences (Gardner).
\end{abstract}

Keywords: Learning; Complexity; TIC; Venezuelan universities, ICT integration models.

\title{
1. Introducción
}

La investigación sobre el impacto de las TIC en los procesos educativos de las instituciones universitarias en Venezuela indica que, a pesar de la rápida expansión en todos los ámbitos sociales y el desarrollo acelerado de nuevas y sorprendentes formas tecnológicas (en hardware y software), la elaboración de propuestas de incorporación al currículo, requieren tanto de un cambio de perspectiva teórica como de un reposicionamiento metodológico.

Para la formulación de un modelo teórico de integración de las TIC a los procesos de enseñanza/aprendizaje en el nivel de educación universitaria, desde la perspectiva de la complejidad, en el sentido introducido por Morin (1983, 1986, 1988, 1992, 1998, 2004), se plantea la ruptura de viejos paradigmas que sustentan el diseño curricular tradicional y el 
planteamiento de un aprendizaje que transcienda lo circunstancial, disciplinar y utilitario, para alcanzar los estándares de lo que definimos como "aprendizaje complejo".

Esta investigación metodológicamente cuali-cuantitativa, abordó las siguientes categorías: (a) las políticas educativas que el Estado ha establecido para orientar el proceso de integración de las TIC a la educación universitaria en Venezuela, (b) la concepción del proceso de enseñanza/aprendizaje predominante en los currículos de educación universitaria, tanto en las instituciones públicas como privadas, (c) el papel de las comunidades integrantes del entorno de las instituciones de educación universitaria estudiadas en el proceso de integración de las TIC, (d) los indicadores del proceso de integración de las TIC a la educación universitaria en Trujillo, Venezuela y (e) la percepción que poseen los docentes y estudiantes universitarios acerca de la utilización de las TIC en el proceso de enseñanza/aprendizaje.

Parte de la investigación y sus resultados ha sido publicada con anterioridad (Lobo et al., 2011; Lobo y Ruiz, 2014; Lobo et al., 2014; Cfr. Rosario et al, 2013; Rosario et al., 2017) y lo relacionado con la última categoría está en proceso de publicación, habiendo sido abordado desde la perspectiva de las representaciones sociales, mediante un estudio de tipo cualitativo, con entrevistas en profundidad, contando como informantes claves con un grupo de 12 profesores adscrito a la universidad autónoma y; a partir de los resultados obtenidos, se identificaron las tendencias más relevantes, se elaboraron y aplicaron cuestionarios a muestras estadísticamente significativas de 60 profesores y 603 estudiantes de las cinco instituciones universitarias seleccionadas para realizar la investigación, asentadas todas en el estado Trujillo (Venezuela), que se identifican como: a) universidad autónoma (UA), b) universidad experimental (UE), c) universidad privada (UP), d) instituto universitario público (IPu) y e) instituto universitario privado (IPr).

Los resultados apuntan a la reconstrucción de las interacciones entre los elementos del proceso para la concreción de un modelo de aprendizaje complejo, holístico, sistémico y autopoiético, que considera no sólo los aspectos tradicionales de instalaciones y entrenamiento, sino también, las representaciones sociales de los protagonistas del proceso educativo, la influencia del entorno, la participación del Estado, tanto en el ámbito nacional como internacional.

Se presentan los aspectos esenciales del Modelo de Integración de las TIC para un Aprendizaje Complejo (MI-TIC-AC) en las instituciones de educación universitaria, como producto de los postulados teóricos y los hallazgos empíricos de la investigación realizada. Se condensan y articulan los análisis e interpretaciones realizadas en los capítulos anteriores con 
la finalidad de entretejer un modelo o sistema teórico que facilite la comprensión y explicación de las interacciones que deben propiciarse entre los diferentes elementos del sistema involucrados en los procesos de enseñanza/aprendizaje mediados por TIC.

Popper (1957) señala que: “Todas las teorías son experimentos, hipótesis provisionales, puestas a prueba para observar si funcionan; y toda demostración experimental es sencillamente el resultado de las pruebas llevadas a cabo con espíritu crítico, en un intento de averiguar dónde yerran nuestras teorías” (p. 87). Luego, el modelo propuesto, habría que ponerlo a prueba para apreciar sus aciertos y deficiencias $\mathrm{y}$, dadas sus características sistémicas y recurrentes, realimentar con la experiencia para mejorarlo.

Algunas teorías toman más tiempo que otras para reunir las condiciones necesarias para su ensayo y prueba. El modelo planteado requiere decisiones y acciones en cada uno de los elementos que conforman el sistema objeto de estudio, identificados como parte de las dos tríadas del contexto universitario: ESTADO - UNIVERSIDAD - ENTORNO SOCIAL (Contexto externo) y PROFESORES - CURRÍCULO - ESTUDIANTES (Contexto interno), según se muestra en la figura 1. Los cambios de manera aislada, en algunos de dichos elementos y en las interacciones correspondientes, sería procedente esperar que, sólo lograsen avances y mejoras parciales, aunque igualmente importantes.

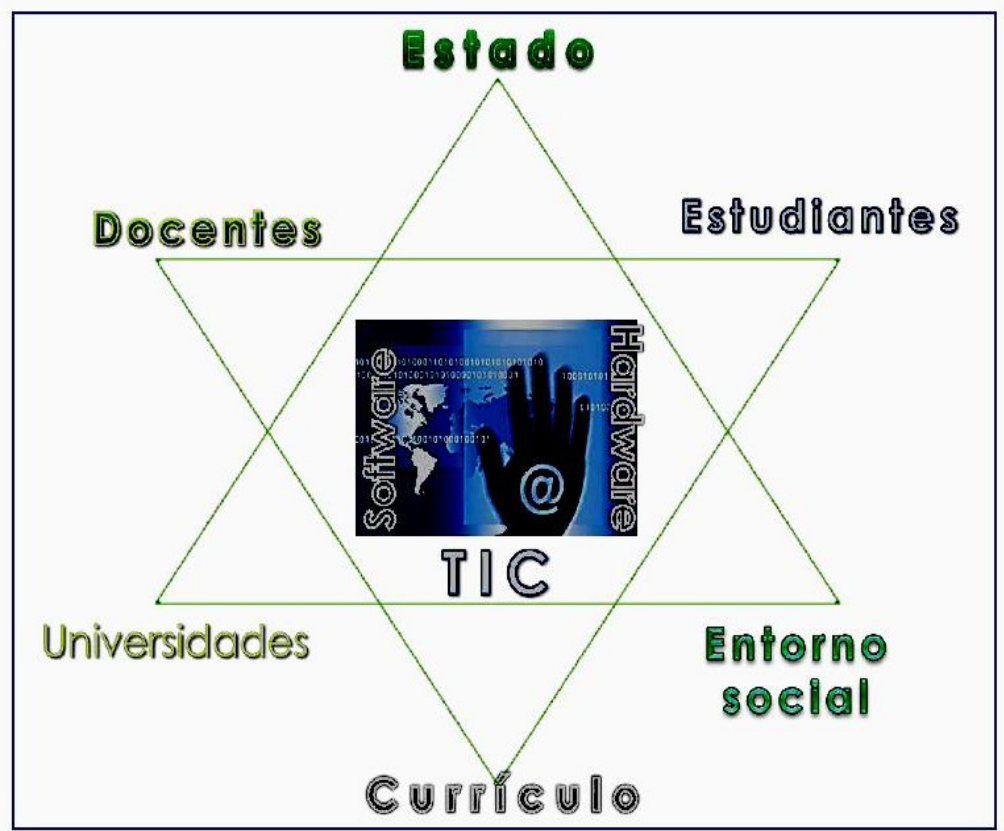

Figura 1. Componentes internos y externos del proceso educativo universitario. Fuente: Autor

La integración de las TIC al proceso educativo universitario no debe ser considerada sólo desde la perspectiva de las instituciones o centros de educación superior, menos aún reducirla a resultados meramente cuantitativos. Es necesario considerar numerosos aspectos cualitativos del proceso, evaluando los efectos que las TIC tienen sobre el aprendizaje en 
niños y adolescentes, aunque al respecto se encuentren opiniones contrapuestas. Así lo plantea Melo Hernández (2018) en su tesis doctoral sobre la integración de las TIC en las universidades colombianas, al afirmar que:

\begin{abstract}
No se trata de la tecnología por la tecnología, sino el manejo de herramientas TIC con sentido pedagógico que posibilitan nuevas formas de enseñanza y aprendizaje en los estudiantes y, además, se proyecta en el uso e interés de estos, de ahí que los modelos didácticos como SAMR, TPACK, TIM, ACOT, MiTiCa, son poco o nada conocidos por los docentes (p. 280)
\end{abstract}

El recorrido racional seguido en esta investigación ha permitido un acercamiento progresivo, desde la perspectiva del pensamiento complejo, a los aspectos socio-contextuales del problema, incluyendo lo internacional, lo nacional, lo local, lo institucional, lo curricular, la práctica docente y las representaciones sociales de profesores y estudiantes universitarios acerca de las TIC en los procesos sociales y educativos. Se juzga entonces, que el análisis e interpretación realizada proveen fundamentos legítimos para emprender el engranaje de diversos elementos, en una construcción nueva y abierta a subsiguientes avances y adaptaciones, como un aporte teórico a un tema de mucha actualidad y controversia.

\title{
2. Modelo de integración de las TIC para un aprendizaje complejo (MI-TIC-AC)
}

Los aspectos más relevantes del Modelo de Integración de las TIC para un Aprendizaje Complejo (MI-TIC-AC) en las instituciones de educación universitaria venezolanas, se explican a continuación:

\section{Objetivos}

A la pregunta ¿Qué se propone lograr a largo plazo? el MI-TIC-AC incluye:

a. Integrar de manera sistemática y eficiente las TIC al proceso de enseñanza / aprendizaje en las instituciones de educación universitaria.

b. Impulsar interacciones de los elementos que conforman el sistema de educación universitaria para el logro de estándares de competencias en TIC de los estudiantes.

c. Garantizar que la integración de las TIC en las instituciones de educación universitaria facilite el aprendizaje complejo en los estudiantes universitarios.

d. Establecer mecanismos de evaluación institucional e interinstitucional concertados acerca del proceso de integración de las TIC, el avance en la implantación del modelo y el impacto en la calidad del aprendizaje.

A la pregunta ¿Cuáles son las metas más inmediatas? el MI-TIC-AC propone:

e. Fomentar el diálogo en torno a la integración de las TIC en las instituciones de educación universitaria. 
f. Llamar la atención sobre la necesidad de organizar el uso de los recursos digitales para la educación universitaria con el fin de optimizar los procesos de enseñanza/ aprendizaje mediados por TIC.

g. Promover los cambios y ajustes necesarios, tanto en los elementos del sistema como en sus múltiples interacciones, a fin de lograr las condiciones para la integración eficiente de las TIC al proceso de enseñanza/aprendizaje.

h. Proporcionar una base teórica de desarrollo del modelo que sea compatible con las diferentes experiencias de las instituciones de educación universitaria y que permita su actualización continua y permanente de acuerdo con los avances tecnológicos, el surgimiento de teorías innovadoras y los cambios del marco normativo y legal.

i. Impulsar la definición de estándares nacionales de desempeño de estudiantes en el aprendizaje con tecnologías digitales para cada uno de los niveles educativos.

\section{Principios}

Los principios que delinean el MI-TIC-AC son los siguientes:

\section{Complejidad.}

El modelo enfrenta el problema, su conocimiento y transformación pertinente, desde la complejidad, considerando inseparables los elementos diferentes que constituyen un todo y verificando la existencia de un tejido interdependiente, interactivo e inter-retroactivo entre el objeto de conocimiento y su contexto, las partes y el todo, el todo y las partes, las partes entre ellas.

\section{Integralidad.}

El modelo propicia la integración de todas las instituciones universitarias y de todos los elementos que conforman sus contextos interno y externo, en un sistema complejo, dialógico e interactivo.

\section{Articulación.}

El modelo estimula la vinculación entre las actividades propias del proceso de enseñanza/aprendizaje con las del resto del quehacer universitario, tales como la investigación la extensión, la administración y la producción, así como también entre los niveles educativos precedentes, el pregrado y el postgrado.

\section{Pertinencia.}

El modelo debe atender las necesidades y demandas de la sociedad del conocimiento relacionadas con la formación técnica, profesional y de postgrado virtual a distancia, además de responder a los retos de la sociedad del aprendizaje, incorporando permanentemente los cambios socioculturales y los avances científicos y tecnológicos, para el desarrollo de la educación para todos a lo largo de la vida. 


\section{Flexibilidad.}

El modelo bosqueja un sistema abierto e interconectado, con una estructura organizativa y normativa adaptable que; relacione las instituciones y sus componentes, estandarice los requerimientos de calidad académica de las unidades curriculares virtuales y provea mecanismos para la prosecución y movilidad de los estudiantes.

\section{Participación.}

El modelo surge del análisis de las representaciones sociales acerca de las TIC de los protagonistas del proceso educativo; su participación futura en la implantación y evaluación de impacto requiere modificar los mecanismos de acceso y participación de todos los actores, para garantizar que tengan la posibilidad de expresar sus opiniones, sentimientos e intenciones a través de las TIC como refuerzos técnicos de la comunicación lingüística. La sustentabilidad del modelo responderá a un proceso de evaluación y seguimiento continuo que permita realizar acciones, revisándolo y adecuándolo permanentemente.

\section{Comunicación.}

El modelo destaca en las TIC para la educación, la comunicación antes que el flujo o almacenamiento de información, la interacción de los usuarios más que las características del hardware o software, los procesos en el que los hablantes, apropiándose del uso de las tecnologías, no se restringen a consumir de forma pasiva la información, sino que logran alcanzar las competencias necesarias para utilizar los recursos con los cuales interpretarla y compartirla, enriqueciéndola.

\section{Regulación.}

El modelo debe implantarse sobre la base de un entramado normativo, legal y reglamentario que garantice transparencia y responsabilidad de cada parte del sistema en los procesos de integración; su planificación, financiamiento, ejecución y evaluación, a partir de criterios técnicos, científicos y académico.

\section{Lineamentos y modelos teóricos de integración TIC}

Se expone a continuación el proceso de construcción teórica de los modelos de comunicación, mediados por TIC, con fines educativos, incluyendo aquellos surgidos antes del advenimiento de la internet y la informática.

\section{Modelo de acción comunicativa}

La Teoría de la Acción Comunicativa de Habermas $(1992,1997)$ constituye el telón de fondo del modelo propuesto. Es la competencia comunicativa de las personas la que puede producir los consensos y disensos que generan los hechos sociales. La acción comunicativa es aquella en la que "los actores buscan entenderse sobre una situación de acción para poder así coordinar de común acuerdo sus planes de acción y con ello sus acciones" (Habermas, 1992; p. 124). 
No se trata de que la sociedad, con todos sus hechos y acontecimientos, pueda explicarse en términos meramente comunicacionales o de interacción lingüística, negando de manera idealista los aspectos materiales de la realidad social, pero, lo que si señala el enfoque habermasiano es que los fenómenos sociales están siempre lingüísticamente mediados y, es mediante este proceso que, los seres humanos se convierten en constructores activos de su Lebenswelt («mundo vital»), y por tanto de su sociedad (Noguera, 1996; Radl, 1998).

Ese esfuerzo tendrá que expresarse mediante un diálogo constante, con algunas "condiciones ideales del habla". Esto es, para que se recreen situaciones ideales de habla, los participantes potenciales en un discurso tienen que tener la misma posibilidad de utilizar actos de habla comunicativos, de manera que puedan iniciar un discurso en cualquier momento, perpetuarlo con réplicas y contrarréplicas, preguntas y respuestas y, además, deben tener la misma posibilidad de realizar interpretaciones, aserciones, recomendaciones, explicaciones y justificaciones, de tal forma que ninguna opinión anterior se sustraiga continuamente de ser tematizada y criticada (Habermas, 1992).

En los medios de comunicación tradicionales estas condiciones están negadas por completo $\mathrm{y}$, en consecuencia, también en los procesos educativos mediados por tales tecnologías. La comunicación es unidireccional y los usuarios simples receptores. Es el caso de la Televisión Educativa, ilustrada en la figura 2(a). En la denominada Web 1.0, la comunicación adquiere otra dimensión, pero sin alcanzar las condiciones ideales. Aparece la comunicación bidireccional y los procesos educativos refuerzan el intercambio de información entre profesores y estudiantes, por ejemplo, a través del correo electrónico, como se muestra en la figura 2(b).

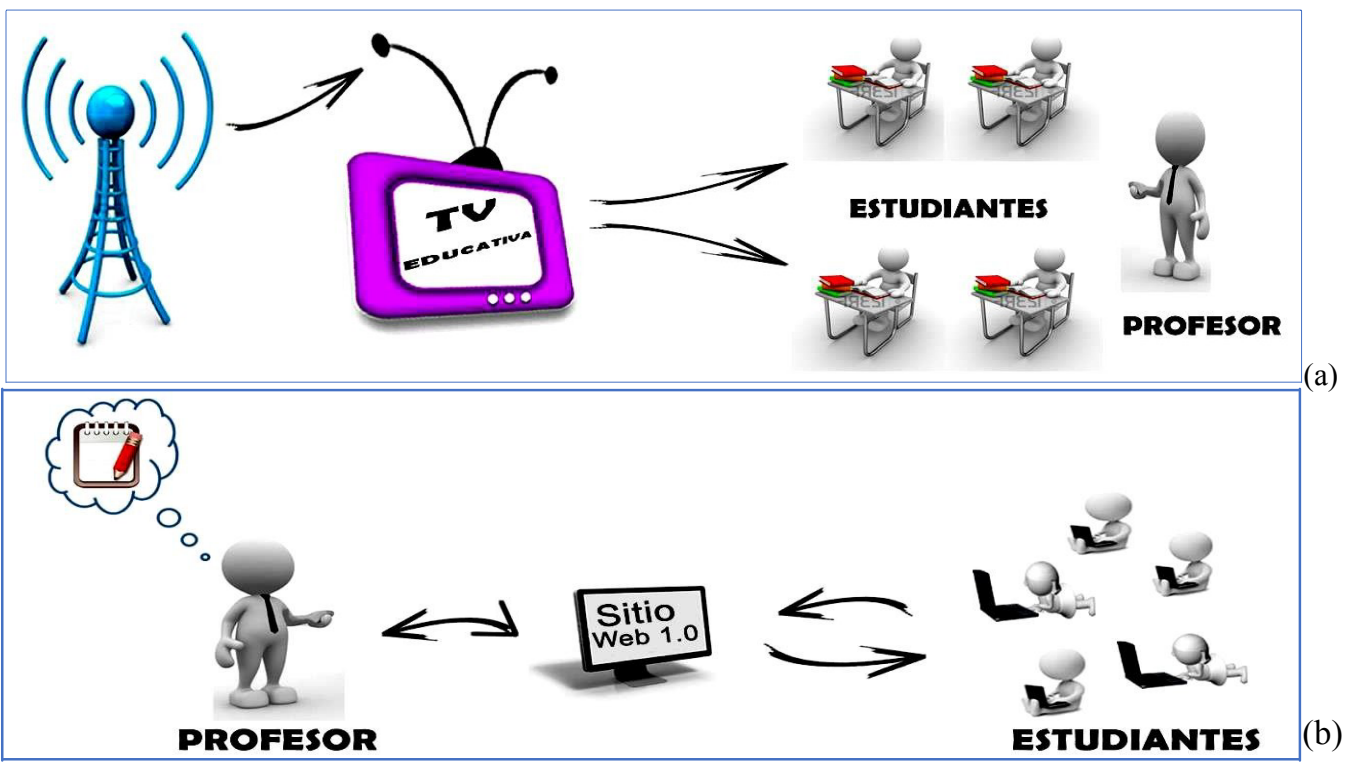

Figura 2. Modelos de interacción comunicativa en la educación en dos momentos tecnológicos diferentes. (a) TV Educativa, (b) Web 1.0. (Fuente: Autor) 
Las condiciones de un modelo de acción comunicativa requieren de mayor interacción, de nuevos flujos de comunicación, los cuales incluyen también actores adicionales a los que tradicionalmente se encuentran en el aula. Es con las características de la Web 2.0 (O’Reilly, 2005) cuando se pueden alcanzar las condiciones ideales de habla; signada por la comunicación multidireccional, la creación de conocimientos aprovechando la inteligencia colectiva y las experiencias de usuario enriquecidas. La figura 3 representa las características del modelo educativo mediado por TIC con base en la teoría de acción comunicativa. Profesores, estudiantes e internautas cuentan con herramientas de edición de toda clase de contenido hipermedia (representadas en la columna de iconos de la izquierda) y, simultáneamente, se multiplican las vías de comunicación e interacción social entre los involucrados en el proceso (cúmulo central de iconos de herramientas Web 2.0 en la figura 3).

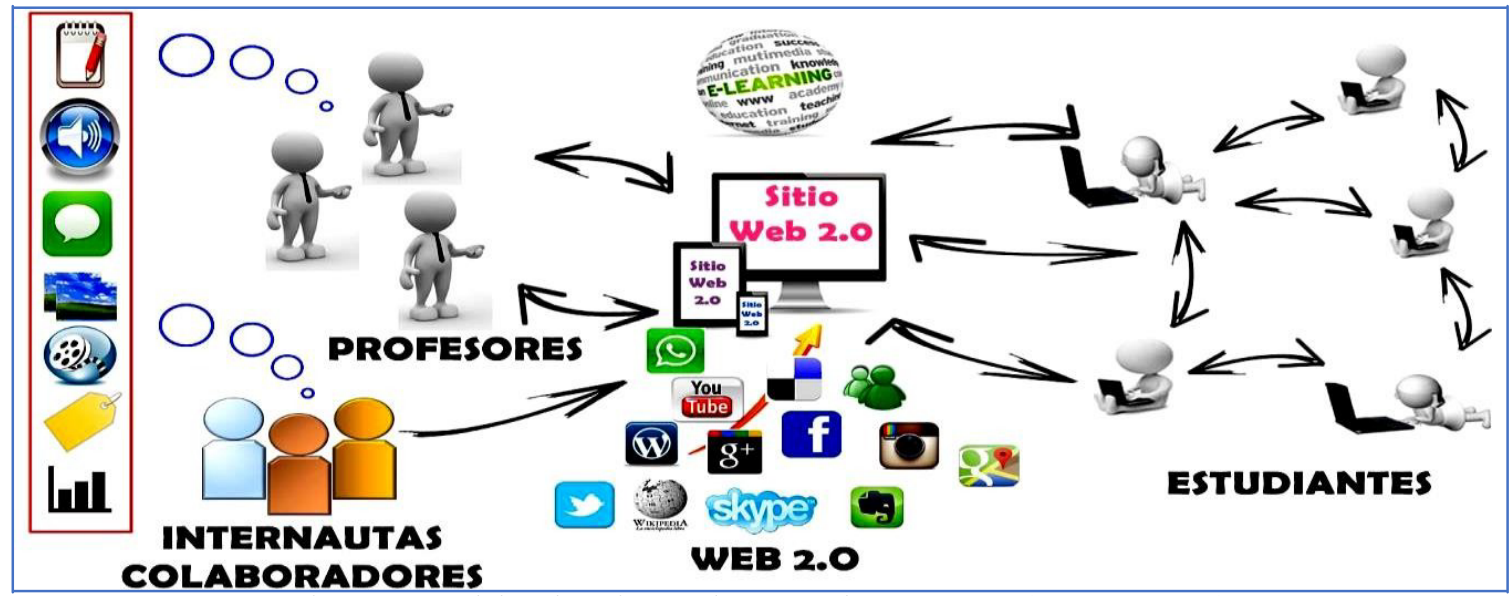

Figura 3. Modelo educativo Web 2.0 con base en TAC (Fuente: Autor)

\section{Modelo sistémico procesal}

La universidad se ha caracterizado, a partir de la Teoría General de Sistemas (Bertalanffy, 1981) como un sistema abierto. Los elementos se condicionan mutuamente y dependen unos de otros, pero, al mismo tiempo responden al entorno. El modelo propuesto tiene, como unidad fundamental, precisamente, el proceso de enseñanza/aprendizaje que se realiza en las instituciones de educación superior. Debe acotarse que la actividad docente no es la única, ni se desarrolla aislada, sino por el contrario, va acompañada de labores de investigación y extensión universitaria, aparte de las propiamente administrativas.

Los elementos que forman parte de la totalidad son múltiples y variados, pero, para el proceso de enseñanza/aprendizaje, los principales son los profesores, los estudiantes y el currículo. Los primeros enseñan, facilitan, orientan y administran el proceso; los segundos aprenden, ensayan, descubren y se forman. El tercero es difuso y omnipresente, se yuxtapone a la universidad, es parte y es todo; los dos primeros elementos se relacionan con y para él, 
sus características determinan la formación y el aprendizaje, es una "serie estructurada de experiencias de aprendizaje que en forma intencional son articuladas con una finalidad concreta: producir los aprendizajes deseados" (Pansza, 1987).

Los elementos que componen un SISTEMA son entrada, salida, proceso, ambiente y retroalimentación. Si es abierto el medio incide en el sistema, y el sistema revierte sus productos en el ambiente. En la entrada se ubican las demandas sociales (matriculares, curriculares, de soluciones) y los recursos y controles impuestos por el Estado, los cuales variaran de acuerdo con la naturaleza de la universidad. Sociedad y Estado son el ambiente, el entorno del sistema; de ellos provienen los insumos o entrada y hacia ellos se vierten los productos o salida.

Todos estos elementos e interacciones aparecen reflejados en el modelo sistémico representado en la figura 4. La UNIVERSIDAD es un sistema abierto por lo que se la frontera que lo delimita se ha representado con una línea (azul) discontinua en forma de ovoide. El proceso de docencia tradicional y el virtual, mediado por TIC, se interceptan en actividades y áreas curriculares compartidas o complementarias y, ambos procesos, con las actividades de extensión e investigación universitaria

El proceso es, por supuesto, el de enseñanza/aprendizaje; tanto el tradicional (presencial) como el mediado por tecnologías digitales (e-learning). El modelo los incluye y los combina (b-learning), pues no se trata de construir un sistema de universidades exclusivamente virtuales.

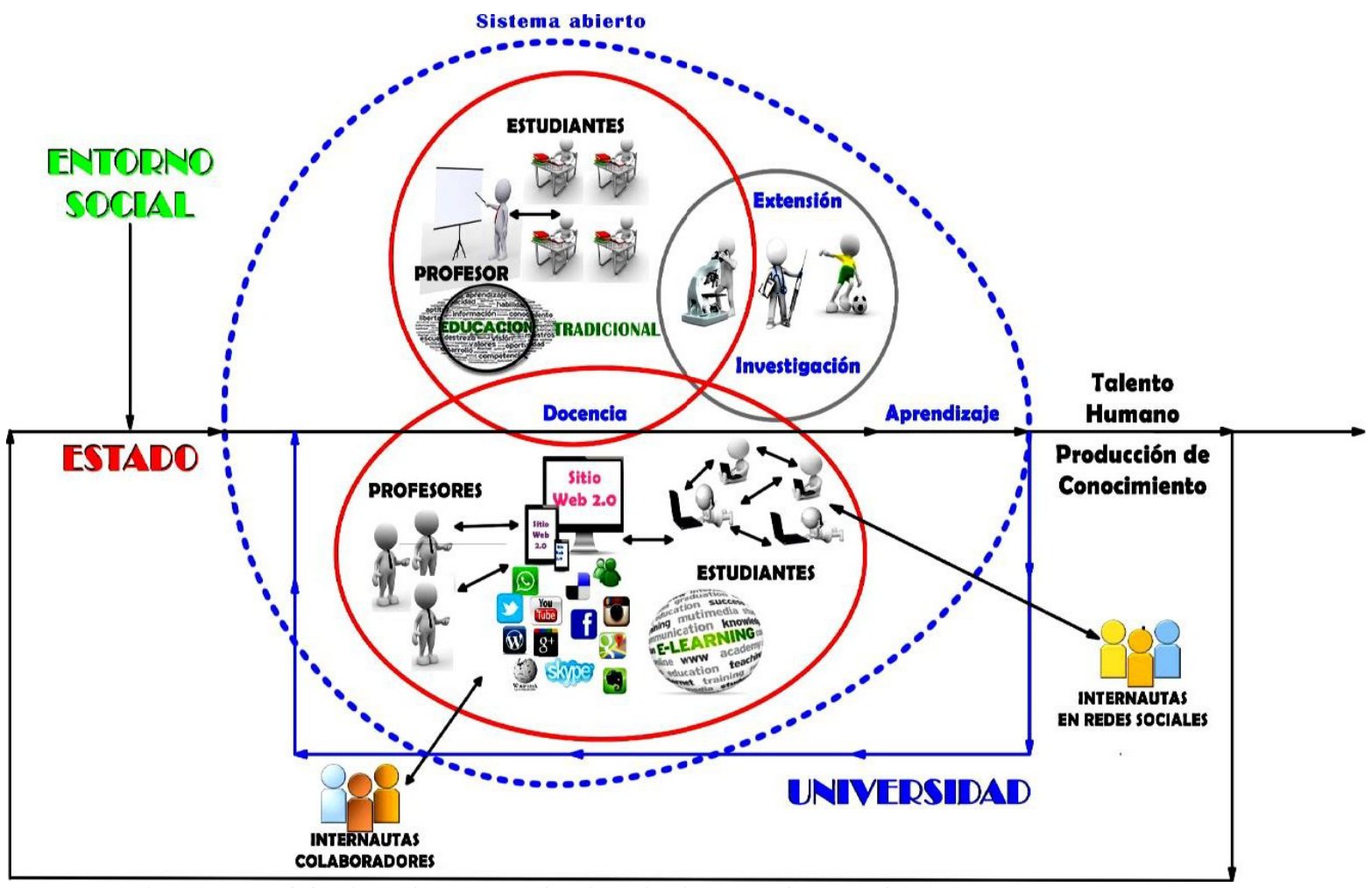

Figura 4. Modelo sistémico procesal universitario pensado para el b-learning. (Fuente: Autor) 
Los procesos virtuales se basan en las herramientas Web 2.0, incluyendo los ambientes virtuales de aprendizaje (AVA) tales como Moodle, los profesores deberían proponer actividades y crear recursos propios adecuados a los requerimientos del currículo; incluso compartir y colaborar para aprovechar experiencias y evitar la duplicación de esfuerzos. El proceso de docencia se alimenta recíprocamente de las actividades de investigación y extensión universitaria, coadyuvando a la concreción del producto primordial del proceso interno: el aprendizaje, justo antes del punto de retorno o retroalimentación (feedback) y de la salida donde aparecen los productos requeridos por el entorno: producción de conocimiento y talento humano de calidad.

La retroalimentación (realimentación, feedback, retroacción o información de retorno) abarca la información que se brinda a partir del desempeño del producto, para cuando haya ocurrido una desviación del plan, determinar por qué se produjo y los ajustes que sería recomendable hacer. Esto obliga a establecer por lo menos dos puntos de feedback: el interno que evalúa continuamente el proceso de formación, a través del aprendizaje obtenido, y determina la calidad del conocimiento adquirido para escalar curricularmente, y el externo que determina la recepción de la información emitida por el entorno sobre el desempeño del talento humano y las bondades del conocimiento producido.

\section{Modelo sistémico procesal complejo}

Desde la perspectiva sistémica, los fenómenos como sistemas abiertos en constante auto organización debido al flujo de intercambio permanente con su entorno responden a la teoría de los sistemas complejos adaptativos, mediante un "proceso en el que se desarrollan emergencias y límites, orientando la evolución del sistema en una flecha temporal sujeta al azar y a la indeterminación" (Bonil et al., 2004).

El sistema "universidad" es un sistema complejo autopoiético que está compuesto por varias partes interconectadas o entrelazadas y cuyos vínculos crean información adicional no visible antes por el observador. Como resultado de las interacciones entre los elementos componentes, surgen propiedades nuevas, emergentes, que no pueden explicarse a partir de las propiedades de los elementos aislados, sino que forman parte de lo que Morin (1990), en palabras ya citadas, denomina: "La complejidad es, efectivamente, el tejido de eventos, acciones, interacciones, retroacciones, determinaciones, azares, que constituyen nuestro mundo fenoménico" (p. 32)

Al contrario del paradigma tradicional de la disyunción, el pensamiento complejo une, reúne, relaciona y aborda los procesos en su constante dinamismo y cambio. (Tobón y Agudelo, 2000), por lo que el modelo sistémico debe alcanzar un nivel mayor de complejidad, 
sin perder de vista su condición de unidad de estudio, esto es, el unitas múltiplex, que implica considerar la unidad y el todo, como parte de una realidad entretejida y compleja. Esto conduce el esfuerzo de formular un modelo que traspase las fronteras de la universidad, que proponga la articulación de decisiones en mayores niveles de complejidad, como es el Estado y la Sociedad, que se entrecruzan, se imbrican y se complementan de diversas maneras con el tema de las TIC para la educación universitaria y, luego también, la dimensión internacional, los organismos multilaterales, pues, como lo señala Castells (1999):

Hemos entrado en un mundo verdaderamente multicultural e interdependiente que sólo puede comprenderse desde una perspectiva plural que articule identidad cultural, interconexión global y política multidimensional.

La representación de la figura 5 es una aproximación simplificada del modelo complejo de integración de las TIC a las universidades. El modelo es gobernado por principios de incertidumbre, recursividad y conjunción, y se construye y reconstruye desde las perspectivas de la acción, dialógica y hologramática. La primera, que resalta el vínculo de pensamiento y acción, tendrá en cuenta tanto la formulación de preguntas como la búsqueda de respuestas y contradicciones; la segunda, que garantiza la interacción de los elementos, el diálogo, la búsqueda de consensos y el respeto a los disensos; y la tercera referida al entendimiento de las realidades planetarias en armonía con las locales, la comprensión de las singularidades institucionales, el respeto a la diversidad en la búsqueda de la unidad

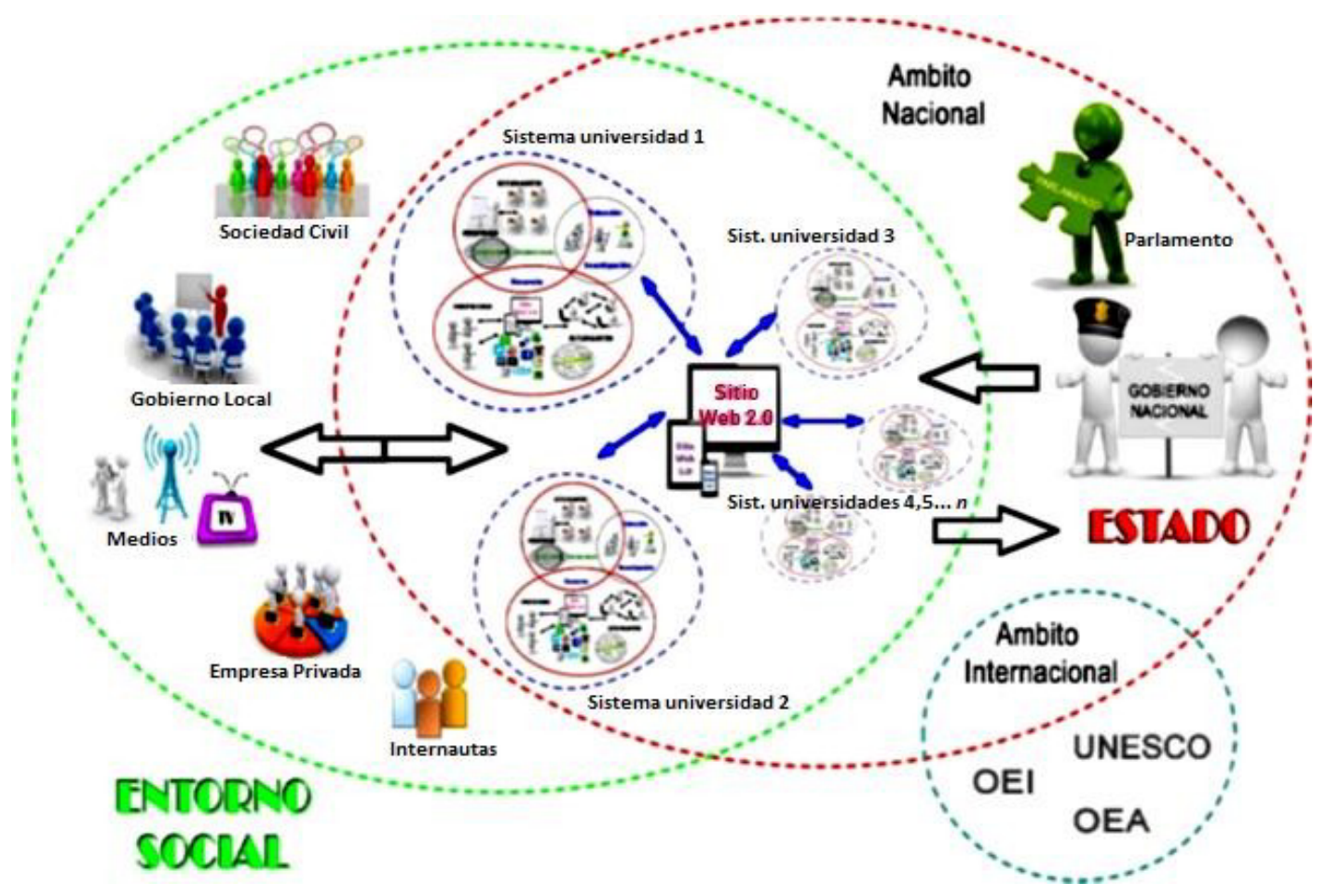

.Figura 5. Modelo sistémico procesal complejo universitario para la integración de las TIC 
El modelo complejo de integración de las TIC implica la interacción universidaduniversidad, la interconexión del esfuerzo pedagógico de las universidades, sin ningún distingo, para capitalizar experiencias, compartir recursos, garantizar la movilidad curricular, asumir estándares uniformes en materia de educación virtual contestes con las exigencias internacionales. Más allá de las redes de ordenadores, nodos y estaciones informáticas se requieren redes de especialistas, de docentes, investigadores y estudiantes. El modelo requiere formas educativas innovadoras que hagan viable la convergencia curricular en torno a un modelo abierto y flexible, comunicativo, basado en competencias, transversalizado e interdisciplinario.

\section{Modelo de aprendizaje complejo}

El Aprendizaje Complejo (AC) no es, ni pretende ser, una teoría, sobre todo en el sentido psicoeducativo con pretensiones de dar explicación de los procesos mentales en el individuo. Es un concepto inacabado sobre alguna clase de aprendizaje deseado que surge de determinado proceso ideal de enseñanza/aprendizaje, que llamaremos complejo siguiendo a Morin (1998, 1999, Cfr. Morin et al., 2003).

\section{Trayectoria del aprendizaje complejo}

Se asume que las características de las actividades realizadas a través de las TIC tienen un gran potencial para captar el interés del estudiante, como primer paso, en la ruta de lograr su compromiso con la regulación de su propio aprendizaje. Luego, la primera característica del aprendizaje complejo es que surge de alguna experiencia que despierta la atención del aprendiz, que pone en funcionamiento su inteligencia emocional (Goleman, 1995), es decir, la inteligencia intrapersonal que viene a ser su equivalente en las categorías de las inteligencias múltiples sugeridas por Gardner (1983) y la última característica es la metacognición (Flavell, 1979), como proceso de aprendizaje madurado y controlado por el aprendiz, quien se convierte en su propio facilitador o maestro, administrando las herramientas que sabe son más apropiadas para lograr que lo aprendido perdure y sea de utilidad.

A la primera la llamaremos aprendizaje afectivo, emocional o intrapersonal, mientras que, al último aprendizaje autorregulado o metacognitivo. Entre estos extremos definiremos el resto de las características del AC. La figura 6 ilustra esta ruta o trayectoria del Aprendizaje Complejo que, además es cerrada y recurrente. 


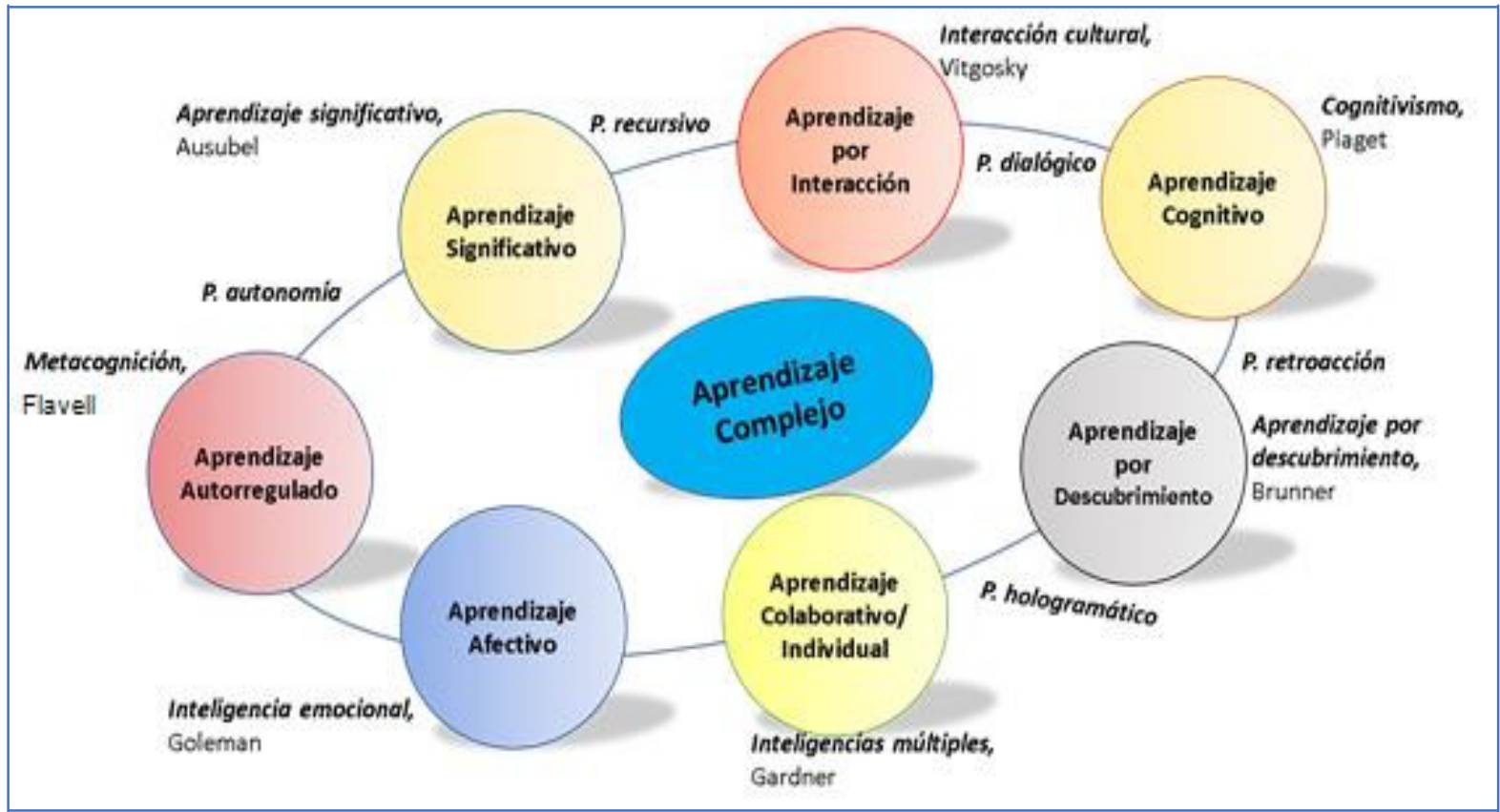

Figura 6. Trayectoria del Aprendizaje Complejo mediado por TIC (Fuente: Autor)

El AC responde al principio hologramático. A la relación entre la unidad y la totalidad, al conocimiento individual y colectivo obtenido de forma simultánea, mientras un grupo trabajo en equipo aprenden algo en común, pero también algo más o diferente individualmente. A esta visión dicotómica propia de la complejidad corresponden dos características adicionales del aprendizaje complejo: el aprendizaje colaborativo o cooperativo que se produce al realizar actividades en las cuales el aprendiz interactúa con otros con un propósito común, intercambiando información y energía, alcanzando en promedio y en común una cierta comprensión de los fenómenos que esté estudiando. Este tipo de aprendizaje se vincula a la inteligencia interpersonal de Gardner; por la facilidad, para quienes la desarrollen, de sacar provecho a situaciones de aprendizaje colectivo.

$\mathrm{Su}$ complemento es el aprendizaje individual o personalizado, que es aquel que hace único a cada individuo, que genera las diferencias a veces notables en los aprendizajes sobre algunas situaciones y, respecto al cual, se debe valorar con mucho cuidado, pues, de manera natural según la Teoría de las Inteligencias Múltiples de Gardner los seres humanos tienen mejor disposición para aprender o resolver problemas de cierta clase, según su tipo de inteligencia: lingüística, lógico-matemática, espacial, corporal kinestésica, musical, naturalista $\mathrm{y}$, las ya mencionadas, interpersonal e intrapersonal. Las TIC facilitan tratar adecuadamente con recursos diversos los rezagos de algunos integrantes del grupo, pues, en muchos casos se puede arribar a la comprensión de cualquier situación o fenómeno siguiendo diferentes caminos 
El principio del bucle de la retroacción que nos compele a formular preguntas y a buscar respuestas y contradicciones, pues siempre queda pendiente algo más que indagar y, por supuesto, algo más que descubrir; explica la siguiente característica del AC, el denominado aprendizaje por descubrimiento, ampliamente teorizado por Brunner (2001), cuya base de fondo es la visión de Piaget $(1999,2007)$ como etapas en el desarrollo temprano del ser humano.

El principio dialógico que nos plantea el diálogo entre sujetos, pero también entre sujeto y objeto, nos orienta hacia una teoría muy respetada conocida como el aprendizaje por interacción de Vigotsky $(1934,1978)$. Se aprende a partir de la interacción cultural, somos parte de una especie especialmente sociable, que adquiere formas de vida (culturas, civilizaciones) muy diferentes, aún en pequeños grupos, la interacción más frecuente es la que determina el comportamiento. También es importante en el contexto el medio ambiente natural, pues las necesidades y retos que nos plantea el medio determinan también el aprendizaje.

El principio del bucle de la recursividad, es decir, la recurrente espiral del saber (la trayectoria infinita) que nos habla del conocimiento como una construcción eterna y continua, donde cada cosa que aprendemos se convierte de inmediato en un conocimiento previo que precede al siguiente, que tendrá el mismo destino y así ad infinitum, se relaciona muy claramente con el enfoque constructivista y, particularmente, con la teoría del aprendizaje significativo de Ausubel (2012, Cfr. Ausubel et al., 1983), que plantea algo que resulta completamente cierto: si el aprendiz carece de los conocimientos previos necesarios que le permitan procesarlo cognitivamente e incorporarlo apropiadamente a sus reflexiones y pensamientos, lo que aprenda tendrá que memorizarlo y no tendrá significado para él.

El principio de autonomía genera una característica más al AC, relacionada obviamente con el aprendizaje autorregulado o metacognitivo, pues se aprende sin requerimientos escolares, se debe aprender también sin gríngolas, con la mente abierta a todas las corrientes del pensamiento humano, atentos a lo que según el criterio propio de cada uno es la idea más cercana que tendremos nunca sobre la verdad o realidad. Se debe procurar que el aprendiz tome decisiones sobre ¿Qué? ¿Cómo? y ¿Por qué? aprender, eso lo conduce a la meta, la metacognición de Flavell (1979).

Esta trayectoria se realiza durante el acto didáctico, mediante un conjunto complejo de situaciones que enfrenta el ser humano a lo largo de su vida, pero, que son inducidas en la escuela y la universidad. Allí surgen primordialmente de las múltiples interacciones estudiante-profesor, estudiante-estudiante y profesor-profesor. Tales interacciones se ven reguladas (estimuladas o desanimadas) por el currículo vigente y, de hecho, la introducción de 
las TIC al proceso de enseñanza/aprendizaje, suponen aspectos renovadores en la concepción curricular implícita en el modelo.

\section{Elementos del modelo de aprendizaje complejo}

El modelo de integración para un aprendizaje complejo en las universidades venezolanas requiere ajustes en cada uno de los elementos que integran el proceso educativo ya ilustrados en la figura 1. Los aspectos característicos y más relevantes de cada elemento y sus relaciones se muestran en la figura 7, es decir, como se sobrepone el MI-TIC-AC entre las dos triadas de elementos del sistema propuestos al inicio de la investigación: UNIVERSIDAD-SOCIEDAD-ESTADO y CURRÍCULO-DOCENTE-APRENDIZ.

Se hace notar que los aspectos del docente y los aspectos del aprendiz están mediados por los aspectos de la interacción que corresponden a la universidad, por un lado, pues es el lugar donde conviven e interactúan de acuerdo con los fines de la Ley, pero también a la(s) red(es) de aprendizaje, que potencian y multiplican la comunicación e interacción entre los protagonistas del proceso de enseñanza/aprendizaje.

Una breve descripción de cada aspecto parece ser necesaria, para comprender, no sólo, las características del modelo de integración propuesto, sino para sopesar la magnitud de los cambios que habrían de producirse en todos los niveles.

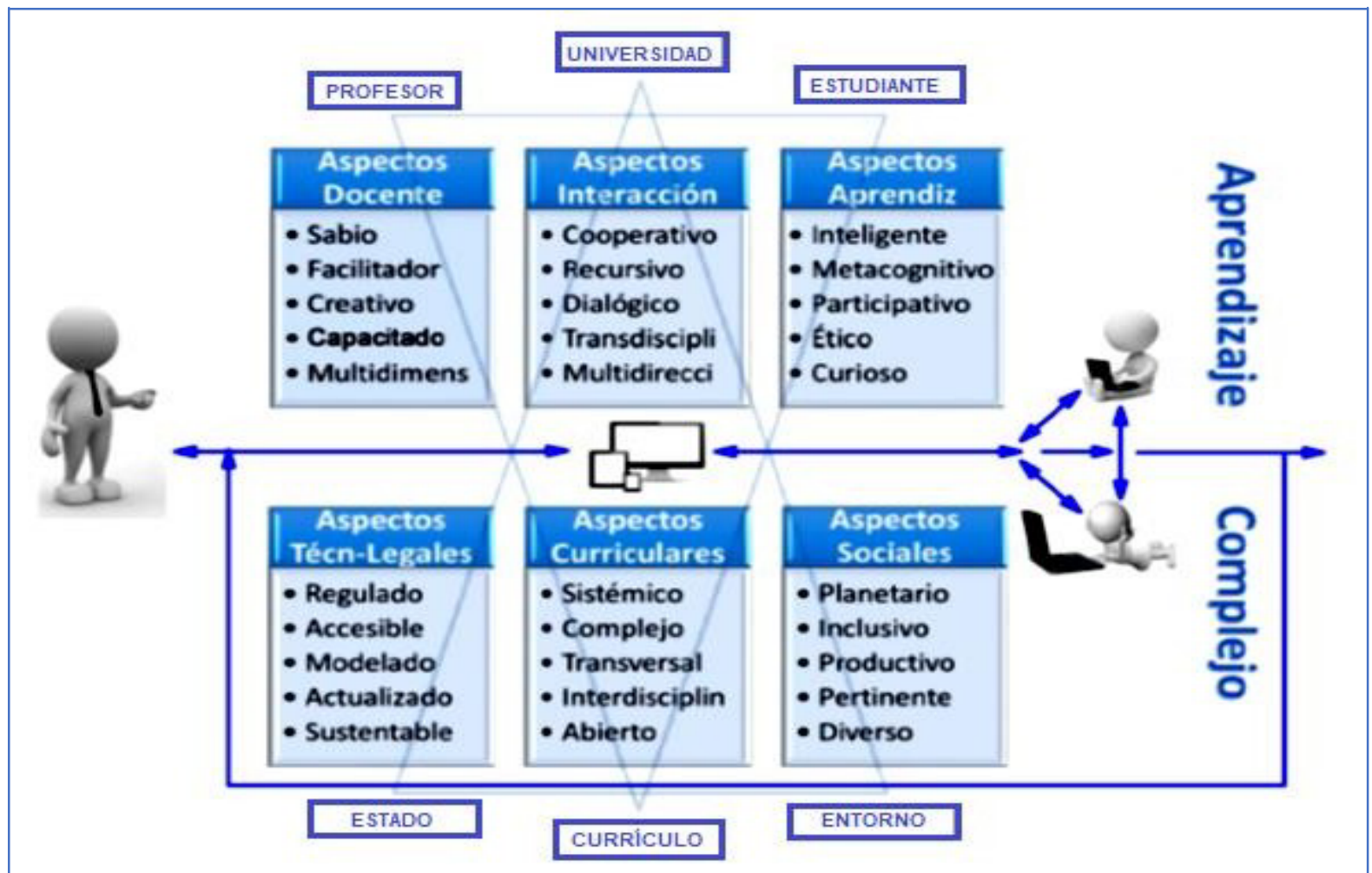

Figura 7. Aspectos del modelo para el aprendizaje complejo mediante la integración de las TIC (Fuente: Autor) 


\section{Aspectos del docente}

El modelo requiere de un docente: sabio para comprender los alcances y limitaciones de su conocimiento, para aceptar equívocos y cambiar de rumbo en su práctica docente, dispuesto a valorar las innovaciones; facilitador de los procesos de aprendizaje de sus estudiantes, que propone y no impone situaciones de aprendizaje, que escucha sugerencias y responde de buen talante todas las preguntas, que produce interacciones sincrónicas y asincrónicas en el espacio virtual y real, que comprende la evaluación como proceso para validar el aprendizaje logrado y no como mecanismo coercitivo; creativo para sobreponerse a las restricciones impuestas por la realidad educativa y lograr vivencias extraordinarias junto a sus estudiantes, para mezclar en el b-learning métodos, estrategias, actividades y recursos para aprender; capacitado en los contenidos, métodos pedagógicos y con competencias en el uso de las TIC e idiomas instrumentales y; multidimensional en su visión compleja del conocimiento del universo, de pensamiento abierto, tolerante y comunicativo, docente e investigador, planificador y administrador de los procesos educativos, orientador y ejemplo de conducta para los estudiantes, cooperador con sus colegas y líder de la innovación dentro de sus respectivos centros educativos, con sentido de pertenencia institucional y ciudadano del mundo, en constante proceso de formación y aprendizaje.

\section{Aspectos del aprendiz}

El modelo estimula la formación de un estudiante: inteligente desde la perspectiva de las inteligencias múltiples, con algunas disposiciones particulares, pero con todas las potencialidades (lingüística, lógico-matemática, espacial, intrapersonal, corporal-kinestésica, interpersonal, musical y naturalista) para encontrar respuestas a los problemas y, también, para generar nuevos problemas y soluciones útiles para la sociedad; metacognitivo de modo que regule su propio aprendizaje, siendo capaz de explicar las propias operaciones que emergen en el ejercicio de los procesos de pensamiento y de tomar decisiones acertadas sobre el tipo de interacciones o experiencias, incluyendo las virtuales, que facilitan su aprendizaje; participativo en todas las fases del proceso educativo, planificando los cursos, definiendo competencias, debatiendo contenidos, atento a la programación y cumpliendo las actividades individuales o grupales, sincrónicas o asincrónicas; ético al relacionarse con su entorno, asumiendo una conducta digna ante la sociedad, el Estado y la universidad, respetuoso de las opiniones ajenas y dispuesto al debate $\mathrm{y}$ al consenso, con valores de honestidad y responsabilidad en todos sus actos, incluyendo el uso que le da a la información contenida en la Web y a las redes de comunicación que puede establecer por ella y, curioso ante todo, buscando perennemente las respuestas inacabadas que se tienen de la realidad compleja que es el universo y cualquier sistema por pequeño y simple que parezca. 


\section{Aspectos de interacción}

El modelo propone interacciones de tipo: cooperativo para que los estudiantes y profesores aborden las tareas de enseñanza/aprendizaje a partir del trabajo colaborativo, que vaya más allá del trabajo en grupos y se convierta en una dinámica permanente para afrontar y solucionar problemas en los espacios universitarios y extrauniversitarios, compartiendo información, intercambiando ideas, consultando a otros profesores y estudiantes de otras asignaturas, universidades, niveles educativos, idiomas y países; recursivo para que la búsqueda del conocimiento y la verdad sea apreciado como interminable, perenne e incierto, de modo que, el valor de lo que aprendemos, está sujeto a cambios, es perfectible y, por tanto, profesores y estudiantes como parte del movimiento de la hélice infinita del saber, se preparan como ciudadanos de la sociedad del aprendizaje, aquella donde el aprendizaje es para todos a lo largo de toda la vida; dialógico para proponer interacciones basadas en el diálogo, como principio fundamental de toda creación humana, entre todos los actores del proceso, como son profesores $<\longrightarrow$ estudiantes, profesores $<\longrightarrow$ profesores, estudiantes $<\longrightarrow$ estudiantes, pero también, estado $<\longrightarrow$ comunidad internacional, estado $<\longrightarrow$ entorno social, estado $<\longrightarrow$ universidad, universidad $<\longrightarrow$ comunidad internacional, universidad $<\longrightarrow$ entorno social, universidad $<\longrightarrow$ universidad, estado $<\longrightarrow$ profesores, universidad $<\longrightarrow$ profesores, estado $<-$ $>$ estudiantes, universidad $<\longrightarrow$ estudiantes y, por supuesto, estudiantes y profesores $<-$ $>$ internautas en redes de aprendizaje; transdisciplinario para ofrecer situaciones de aprendizaje en las que el estudiante de una carrera universitaria trabajen en problemas que generalmente no son apreciados como de su "especialidad", de manera que, su aprendizaje sea enriquecido por experiencias reales en las que individual o cooperativamente deba afrontar y aportar soluciones desde la perspectiva de su formación profesional y; multidireccional porque las cuatro propiedades anteriores se basan en la existencia de múltiples canales de interacción y contacto, desde el que se realiza cara a cara, en el aula y laboratorio, hasta las diversas formas de comunicación de múltiples direcciones que brindan las TIC.

\section{Aspectos técnicos-legales}

El modelo requiere para su funcionamiento de condiciones que deben ser garantizadas por el Estado primordialmente, pero también, la universidad y otras instituciones; por ejemplo, debe ser: regulado para que haya garantías legales que faciliten el desarrollo de la educación virtual, en todas sus modalidades, se establezcan estándares de calidad de las actividades educativas on-line y se reglamenten la participación (interacciones) de los elementos que forman el sistema modelado, accesible para que sea posible la participación de todos los profesores y estudiantes universitarios del país, no sólo por contar con equipos 
terminales personales o institucionales, sino por la existencia de una conexión veloz, fluida, estable y permanente a las plataformas virtuales y, en general, a cualquier sitio $W e b$ de interés académico; modelado para que sea asumido por todas las instituciones de educación universitaria de la región, manteniendo las diferencias necesarias, pero, abriendo posibilidades de interacción y cooperación de acuerdo al modelo; actualizado para que se vaya ajustando a los avances tecnológicos, científicos y pedagógicos, asumiendo el cambio como algo permanente y necesario, preparado para las innovaciones que la informática, la telemática y la robótica nos tiene reservadas en el futuro y, sustentable porque debe contar con los recursos materiales y humanos necesarios para su implantación y operatividad, por lo cual, las políticas del Estado, la universidad y la sociedad en general deben privilegiar el financiamiento de programas de dotación de equipos de última generación, robustos y seguros, así como, de formación del talento humano para la operación de equipos, diseño de software, didáctica virtual, etc.

\section{Aspectos sociales}

El modelo debe funcionar en condiciones que reproduzcan los fines de la educación en la sociedad, debe ser: planetario en una visión comprometida del mundo donde mora la humanidad y el resto de los seres vivos, a través de la asombrosa ventana de internet que permite asomarse a los confines del espacio sideral, a cualquiera de los ecosistemas existentes sobre la Tierra y a las culturas y civilizaciones del pasado y del presente, con sólo hacer clic; inclusivo para impedir que la tecnología incremente los desequilibrios sociales y reducir las brechas social y digital al mismo tiempo, de modo que hace falta toda la sinergia del país, de todas sus instituciones para lograr incorporar en el modelo de integración, aparte de las universidades, las instituciones de educación media, las escuelas públicas y privadas, los institutos de capacitación de adultos, los gremios profesionales y las academias, las empresas públicas y privadas que puedan aportar a este esfuerzo, los gobiernos locales, regionales y nacional para sembrar en el país las bases para la construcción de las sociedades de la información $>$ conocimiento $>$ aprendizaje; productivo en la formación de técnicos $\mathrm{y}$ profesionales, de talento humano de alta calidad, con competencias en su área de formación específica, pero también, en el diseño y uso de herramientas digitales e idiomáticas necesarias para enfrentar los retos del siglo XXI; pertinente porque se procesa a partir de la realidad socioeducativa presente, adaptando su funcionamiento a las fortalezas y deficiencias con que cuenta el sistema, procurando mejorar en los aspectos de calidad y cobertura educativa, para dar respuesta a las demandas y solución a los problemas planteados por el entorno social y; diverso, pues la unificación de criterios y la reunión de esfuerzos institucionales no implica la hegemonía del modelo que debe ajustarse a la diversidad propia de la complejidad. 


\section{Aspectos curriculares}

Para que el modelo tenga éxito deben producirse cambios en el currículo partiendo de las siguientes características: sistémico, para que se establezcan las características de un sistema abierto, y no cerrado como el actual, mucho más vinculado al entorno natural y social $\mathrm{y}$ menos a las aulas cerradas y herméticas, con ventanas al mundo virtual por las que profesores y estudiantes deben asomarse al analizar cualquier contenido programático, con aspectos equivalentes en distintas instituciones y recursos intercompartidos y, sobre todo, retroalimentado por los múltiples feedback producidos en su desarrollo, para asumir rápida y oportunamente cambios inteligentes y necesarios; complejo, para que garantice una formación integral del aprendiz, con una visión multilateral del mundo que los rodea, con conocimiento de lo disciplinar, pero también de lo diverso, lo imprevisto, lo incierto, involucrando al estudiante en actividades de docencia, pero también, en las de investigación y extensión en las comunidades, cultivando la disposición a aprender, trabajar y ayudar a los demás, combinando la educación presencial con e-learning, b-learning y m-learning, con recursos interactivos y capaces de sorprender al estudiante, con materiales propios o procedentes de redes de aprendizaje de todo el mundo, en español, pero también en otros idiomas; transversal, de modo que no se pretenda resolver la integración de las TIC agregando una o dos asignaturas al currículo que tengan que ver con "eso", sino, al contrario, se establezca realmente como un eje transversal en las actividades que se desarrollan en cada una de las unidades curriculares, sean estas cursos, seminarios, laboratorios, seminarios, pasantías o trabajos especiales, para que la formación en TIC sea realmente una herramienta agregada en el proceso de formación profesional y como ciudadano de la sociedad del aprendizaje por venir; interdisciplinar mediante el reconocimiento de cursos mediados por TIC, con estándares de calidad determinados, que ofrezcan otras carreras y/o universidades, seleccionados por el estudiante de acuerdo a sus intereses y planes de formación con experiencias en áreas diferentes a su especialidad y con el concurso de otros estudiantes de diversas carreras para abordar interdisciplinariamente el estudio y solución de cierto problema $\mathrm{y}$, abierto, porque sólo con un modelo curricular abierto se puede aprovechar el enorme potencial que tienen las TIC para el proceso de enseñanza/aprendizaje y, posteriormente, para el desempeño técnico y profesional de los egresados universitarios; de allí que, se tiene que establecer también los estándares de formación en TIC de los estudiantes universitarios, independientemente de la institución en la realice sus estudios. 


\section{Conclusiones}

El modelo de integración de las TIC a las universidades para lograr un aprendizaje complejo se estructuró a partir del análisis de los resultados obtenidos durante la investigación y que permitieron conocer e interpretar la participación de cada uno de los actores involucrados. El modelo se propone la promoción de cambios en los elementos del sistema como en sus múltiples interacciones, a fin de lograr las condiciones para la integración eficiente de las TIC al proceso de enseñanza/aprendizaje. Agrega una base teórica para el desarrollo del modelo compatible con las experiencias de las instituciones de educación universitaria y que permita su actualización continua y permanente de acuerdo con los avances tecnológicos, el surgimiento de teorías innovadoras y los cambios del marco normativo y legal. Impulsa la definición de estándares nacionales de desempeño de estudiantes en el aprendizaje con tecnologías digitales para cada uno de los niveles educativos.

Los indicadores de integración a las instituciones universitarias, en el contexto estudiado, revela los limitados avances logrados en materia de incorporación de las TIC al currículo a través de las plataformas virtuales institucionales. Son pocas las unidades curriculares que se desarrollan mediante Ambientes Virtuales de Aprendizaje (AVA) y, menos aún, las carreras o programas de postgrado totalmente virtuales y a distancia. Los programas de inducción a las plataformas no han sido exitosos, lo que resulta contradictorio con el estudio de representaciones sociales hecho a los profesores. Más preocupante aún es que los recursos para el aprendizaje suministrados a través de los cursos on-line son documentos en formatos ofimáticos semejantes a guías de estudio y presentaciones visuales, sin ningún valor agregado.

El modelo surge progresivamente basándose en las teorías que fundamentaron el estudio. Primero un modelo que explica la comunicación a través de la Web 2.0 a partir de la Teoría de la Acción Comunicativa de Habermas, Luego un modelo sistémico, que abarca el anterior, pero que, agrega los elementos propios de la Teoría General de Sistemas de Bertalanffy, para ilustrar la universidad como sistema abierto. Un nivel más y se llega al modelo sistémico complejo que, conservando las características de los anteriores, multiplica en atención a la idea de complejidad de Morin, todas las instituciones universitarias con sus semejanzas y diferencias, contenidas en dos sistemas de mayores dimensiones que se entrecruzan como son el Estado y el entorno social. Desde esta perspectiva se hizo el estudio. 
El modelo propende el aprendizaje complejo, como un concepto inacabado, como la aproximación al conocimiento de la complejidad. Su concreción se plantea como una ruta a través de experiencias de aprendizaje basadas en las más importantes teorías de aprendizaje y en la de las inteligencias múltiples especialmente. Los aprendizajes escalados son vinculados a los principios del pensamiento complejo de Morin que dan cuenta del camino para acercarse al conocimiento. Se llama trayectoria a la ruta cerrada y recurrente que lleva desde el Aprendizaje Emocional hasta el Aprendizaje Autorregulado.

El modelo propone seis conjuntos de aspectos primordiales que forman parte de los ejes de interacción formados por las tríadas de elementos constituyentes del sistema. Los aspectos del docente y los aspectos del aprendiz se complementan con los aspectos del currículo y, al mismo tiempo obran con los de interacción, representados por la universidad como espacio de encuentro. Los aspectos técnico-legales, asociados al Estado junto a los aspectos del entorno social, completan la tríada con los aspectos de interacción que nuevamente simboliza la universidad.

La incorporación de las nuevas tecnologías a las aulas universitarias pasa por realizar una profunda revisión de las características del currículo universitario actual, pues, a pesar de los avances en las visiones y teorías que sustentan los actuales diseños curriculares; tales como las de currículo abierto, flexible, transversalizado, inter y transdisciplinario, integral, adaptable, sustentable, pertinente y otras categorías, la verdad revelada por el estudio es que el currículo real, también llamado oculto, se encuentra atrapado en prácticas estáticas, rígidas, inflexibles y cerradas. Los cambios programáticos propuestos deben abarcar, aparte de los planes y programas de estudio; toda la práctica docente para incorporar y aprovechar el potencial de las tecnologías de información y comunicación, evitando trasladar al formato digital las prácticas tradicionales.

El entorno social de las universidades; compuesto por las comunidades aledañas, los gobiernos locales y regionales, las organizaciones civiles, la empresa privada, entre otros elementos, son determinantes para la integración de las TIC en las todas actividades sociales y culturales, incluyendo la educación. En el contexto geográfico del estudio se encuentran dificultades y serias limitaciones al analizar factores como: aporte de los gobiernos municipales y regional a los servicios de soporte, en materia de TIC para la educación; calidad y costos de los servicios telemáticos tanto públicos como privados; constancia del suministro de energía eléctrica, locales o salas de internet públicas y privadas, etc. 


\section{Referencias}

AUSUBEL, D. P. (2000): Adquisición y retención del conocimiento. Una perspectiva cognitiva. Trad. Genis Sánchez Barberán, Ediciones Paidós Ibérica, Barcelona (España), 2002.

AUSUBEL, D.P.; NOVAK, J.D. y HANESIAN, H. (1978). Psicología educativa: un punto de vista cognoscitivo. Trad. Mario Sandoval, Editorial Trillas, México, 1983.

BERTALANFFY, L (1968): Teoría general de los sistemas. Fundamentos, desarrollo, aplicaciones. Trad. Juan Almela, México: Fondo de Cultura Económica, 1989.

BONIL, J.; SANMARTÍ, N.; TOMÁS, C. y PUJOL, R. M. Un Nuevo Marco para Orientar Respuestas a las Dinámicas Sociales: El Paradigma de la Complejidad. Investigación en la escuela, 53. pp. 10-20, 2004, Sevilla. Acceso: 06-02-10, Disponible: http://ipes.anep.edu.uy/documentos/curso dir 07/modulo4/materiales/paradigma.pdf.

BRUNNER, J. Preguntas desde el Siglo XXI. Perspectivas, v. 4, n. 2; p. 203-211, 2001.

CASTELLS, M. (1999). La Era de la Información. Madrid: Alianza, Volumen 1, La sociedad Red.

FLAVELL, J.H. Metacognition and Cognitive Monitoring. A New Area of Cognitive Developmental Inquiry. American Psychologist, v. 34 n. 705-712 p. 906, 11 Oct 1979.

FLAVELL, J. H. (1993) El desarrollo cognitivo, Madrid: Editorial: Antonio Machado.

GARDNER, H. (1983). Estructuras de la mente. La teoría de las inteligencias múltiples. México: Fondo de Cultura Económica, 2001.

GOLEMAN D. (1995). Emotional Intelligence: Why It Can Matter More Than IQ. Bantam Books: New York, USA.

HABERMAS, J. (1992). Teoría de la Acción Comunicativa, vol. I. Madrid: Taurus.

HABERMAS, J. (1997). Teoría de la acción comunicativa: complementos y estudios previos. Madrid: Ediciones Cátedra.

LOBO, H.; RUIZ, L.; PACHECO, A.; MORÓN, F.; DELGADO, F., Uso de las tecnologías de información y comunicación (TIC) en la enseñanza impartida en el Ciclo Básico de Ingeniería en el NURR-ULA. Ciencia e Ingeniería, v. 32, n. 02, p. 85-94, abril-julio 2011. ISSN 1316-7081. Editorial Universidad de Los Andes. Acceso: 12 de enero de 2019 [en línea]: Disponible en: http://www.redalyc.org/articulo.oa?id=507550792005.

LOBO, H.; RUIZ, L. La comunicación en las tecnologías de la información. AGORA Trujillo. Venezuela, v. 17, n.33, pp. 41-65, enero-junio 2014. ISSN 1316-7790. Editorial: Universidad de Los Andes. Acceso en: 12 enero 2019 [en línea]: Disponible en: http://www.saber.ula.ve/handle/123456789/39785.

LOBO, H.; ROSARIO, J.; MATERÁN, I.; PACHECO, A.; MORÓN, F.; RUIZ, L. Las TIC en el proceso de enseñanza/aprendizaje de las ciencias naturales en las universidades del estado Trujillo-Venezuela: Un estudio de indicadores. Revista Internacional de Tecnología, Ciencia y Sociedad, v. 03, n. 01, p. 29-44, jun. 2014. ISSN 2530-4895. Editores: Global Knowledge Academics. Acceso: 12 enero 2019 [en línea]. Disponible en: https://journals.epistemopolis.org/index.php/tecnoysoc/article/view/1178.

MELO, M. E. La integración de las TIC como vía para optimizar el processo enseñanzaaprendizaje en la educación superior en Colombia. Tesis (Doctorado en Empresa, Economía y Sociedad) - Universidad de Alicante, España, 2018. 
MORIN, E. (1977). El Método I: La Naturaleza de la naturaleza. Trad. Ana Sánchez y Dora Sánchez, 2001. Ediciones Cátedra: Madrid.

MORIN, E. (1980). El Método II: La vida de la vida. Trad. Ana Sánchez, 1983, Ediciones Cátedra: Madrid.

MORIN, E. (1986). El Método III: El conocimiento del conocimiento. Trad. Ana Sánchez, 1988, Ediciones Cátedra: Madrid.

MORIN, E. (1991). El Método IV. Las Ideas. Trad. Ana Sánchez, 1992, Ediciones Cátedra: Madrid.

MORIN, E. (1990). Introducción al pensamiento complejo. Trad. Marcelo Pakman, 1998, Gedisa: Barcelona, España.

MORIN, E. (1999). Los siete saberes necesarios para la educación del futuro. UNESCO: Paris, Francia.

MORIN, E.; CIURANA, E. R. y MOTTA, R.D. (2003). Educar en la era planetaria. Gedisa: Barcelona, España.

MORIN, E. La Epistemología de la Complejidad. Gazeta de Antropología; n. 20, Texto 2002, feb. 2004. ISSN 2340-2792. Editores: Grupo de investigación Antropología y Filosofía Departamento de Filosofía-Universidad de Granada, España. Acceso: 01 enero 2019 [en línea]. Disponible en: http://www.gazeta-antropologia.es/?p=2841. Este texto corresponde a las páginas 43-77 de L'intelligence de la complexité, editado por L'Harmattan, París, 1999.

NOGUERA, J. A. (1996). La teoría critica: de Frankfurt a Habermas una "traducción" de la teoría de la acción comunicativa a la sociología. Universitat Autònoma de Barcelona. Departament de Sociologia. Papers n. 50, p.133-153, 1996. Acceso: 01 enero 2019 [en línea]. Disponible en: https://ddd.uab.cat/pub/papers/02102862n50/02102862n50p133.pdf.

O'REILLY, T. What Is Web 2.0. Design Patterns and Business Models for the Next Generation of Software. 30 de noviembre 2005. Portal de O-Reilly. Acceso: 02 enero 2019 [en línea]. Disponible en: https:/www.oreilly.com/pub/a/web2/archive/what-is-web20.html.

PANZSA, M. (1987). Notas sobre planes de estudio y relaciones disciplinarias en el currículo. Perfiles educativos, 36, pp. 16-34.

PIAGET, J. (1999). La Psicología de la Inteligencia. Crítica: Barcelona, España.

PIAGET, J. (2007). La representación del mundo en el niño. Morata: Madrid.

POPPER, Karl (1957). El objetivo de la ciencia. En Miller, D. (ed.). Popper: escritos selectos. FCE. 2006; "The Aim of Science”. Ratio. 1.

RADL Ph. R. (1998). La teoría del actuar comunicativo de Jürgen Habermas: un marco para el análisis de las condiciones socializadoras en las sociedades modernas. Santiago de Compostela. España. Papers 56, pp. 103-123

ROSARIO, J. R.; LOBO, H.; RIVERO, D.; BRICEÑO, J.; VILLARREAL, M. Las TIC para el proceso enseñanza-aprendizaje en los laboratorios de Física en el nivel universitario en el estado Trujillo, Venezuela. Revista Internacional de Tecnología, Ciencia y Sociedad, [S.1.], v. 02, n. 02, junio 2013. ISSN 2530-4895. Editores: Global Knowledge Academics. Disponible en: https://journals.epistemopolis.org/index.php/tecnoysoc/article/view/1278. Acceso: 12 ene. 2019. [en línea] 
ROSARIO, J. R.; DÍAZ, J.C.; RIVERO, D.; LOBO, H.; BRICEÑO, J.; VILLARREAL, M.; MATERÁN, I. N.; BRICEÑO, J. R.; PACHECO, A. C. Proceso Enseñanza-Aprendizaje en los Laboratorios de Física de las Universidades Venezolanas Mediante el uso de las TIC. Revista Academia - Trujillo - Venezuela - v. 16. n. 38, p. 7-21, julio-diciembre 2017. ISSN 1690-3226- Editorial Universidad de Los Andes. Acceso: 12 de enero de 2019 [en línea]: Disponible en: http://erevistas.saber.ula.ve/index.php/academia/article/view/9432/9387.

TOBON, S. y AGUDELO, H. (2000). Pensamiento complejo y formación humana en el sistema educativo colombiano. En Memorias del Primer Congreso Internacional de Pensamiento Complejo, Vol. II. Bogotá: Ministerio de Educación Nacional.

VYGOTSKY, L. (1934). Pensamiento y lenguaje. Trad. José Tosaus, Barcelona (España), Ediciones Paidós, 2010.

VYGOTSKY, L. (1978). El desarrollo de los procesos psicológicos superiores. Trad. Silvia Furió, Barcelona (España), Crítica, 2009. 